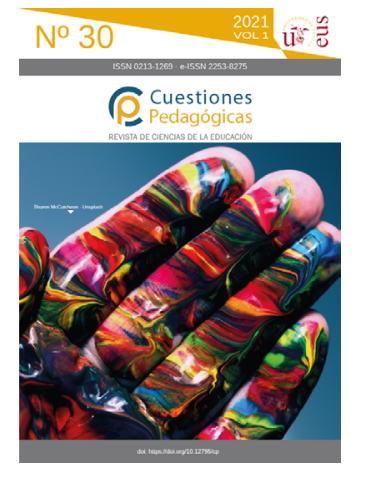

\title{
Revisitando la educación popular en el centenario de Paulo Freire
}

\author{
Revisiting Popular Education in Paulo Freire's centenary
}

Recibido: 13/11/2020 | Revisado: 05/05/2021 | Aceptado: 08/06/2021 |

Online first: 10/06/2021 | Publicado: 01/07/2021

\begin{abstract}
Resumen: Con una larga tradición, la educación popular ha sido durante mucho tiempo un referente para las prácticas educativas que pretendían una mayor autonomía para las personas y una sociedad más justa. Los contextos geográficos y conceptuales que señalan su nacimiento y desarrollo son muy variados. En nuestro entorno más cercano, las corrientes de pensamiento y las prácticas ligadas con América Latina, y con especial relevancia para la obra de Paulo Freire, son las que más influencia e importancia han tenido.

En este artículo pretendo revisar algunas de las ideas que influyen en el desarrollo de la educación popular, así como las metodologías que le dan forma. En concreto, voy a centrarme en las aportaciones de las teorías de la desescolarización, y de metodologías como la investigación participativa, esencial para una construcción colectiva del conocimiento. En una segunda sección mencionaré algunos aspectos metodológicos que priman la interacción social, el diálogo y la participación.

A modo de conclusión, presentaré dos de las críticas más comunes realizadas tanto a la obra de Freire, como a la educación popular - el papel de la escuela como adoctrinadora y la posición de la persona educadora. A partir de ahí, intentaré resaltar la actualidad y relevancia de la educación popular.
\end{abstract}

Palabras clave: Educación comunitaria, educación popular, métodos activos, métodos de investigación, tendencias educativas, Paulo Freire.
Abstract: Popular education has a long tradition as a reference to educational practices looking for people autonomy, and a fairer society. Even both conceptual and geographical contexts that sign its birth and development are varied, in our own context the most important trends are related to Latin-American, with special reference to Paulo Freire's work.

This article is an attempt to review some of the ideas that have influenced the development of the popular education, and the methodologies that shape it. Specifically, I am going to focus on the contributions of the theories of deschooling, and in methodologies as participatory research that is a key element to think on the collective creation of knowledge. In a second section of the article, I will mention the methodological elements that potentiate social relationships, dialogue and participation.

As a conclusion, I will present two of the more common critiques conducted either Freire's work or popular education - the role of the school as indoctrinated, and the role of the educator. Then, I will try to emphasise the relevance of popular education at present time.

Keywords: Activity method, community education, popular education, research methods, educational trends, Paulo Freire. 
Durante las décadas de 1960 y 1970 se desarrolla en América Latina un importante movimiento educativo denominado Educación Popular (EP a lo largo de todo el texto). El máximo representante de ese movimiento es, posiblemente, Paulo Reglus Neves Freire.

Es cierto es que esta tradición educativa no puede ser circunscrita ni al espacio geográfico ni a la época histórica que he señalado. No obstante, existe un cierto acuerdo en considerar esas fechas y ese espacio geográfico, debido, sobre todo, a la obra de Paulo Freire y a la publicación de Pedagogía del Oprimido (Kane, 1999).

Algunos de los antecedentes de la EP se encuentran, también, en América Latina. Tiana (2021) propone como uno de ellos las campañas de alfabetización emprendidas en México alrededor de 1923 por José Vasconcelos. También destaca como otro referente el trabajo de las personas exiliadas desde España tras el golpe de estado y que habían participado en 'Las Misiones Pedagógicas'. Se refiere, en concreto, a actividades en Argentina, Uruguay, Ecuador, Cuba o Guatemala. En algunas de ellas colaboraron Rafael Albertí, Juan Ramón Jiménez o Zenobía Camprubí (Tiana, 2021, p. 248). En Europa es posible considerar como un antecedente en la búsqueda de referentes de la EP la obra de Grundtvig (1991).

En todos los casos, uno de los elementos definitorios es que la educación es una herramienta para el cambio social y para que las personas puedan cuestionarse críticamente sobre sus vidas y sus experiencias (Crowther, 1999). En esta dirección se ha insistido en el carácter político de la EP. Que la educación es una práctica política es un elemento destacable en el pensamiento de Paulo Freire (Mayo, 1999).

Las dos grandes ideas-fuerza de la educación popular son, entonces, que la educación es un proceso en el que las personas reflexionan sobre su vida y sus experiencias dentro de un contexto concreto, y que la educación sirve para imaginar y construir otras realidades.

Para que la educación popular contribuya al cambio social tiene que conectar con las fuerzas que mueven a las personas a actuar. Tiene que estar unida a las raíces culturales que la sustentan $-y$ que, a su vez, ayudan a sustentar (Crowther, 1999, p. 34).

Se puede abordar la EP desde dos aproximaciones diferentes. Por un lado, las aportaciones teóricas que determinados autores y autoras hacen a la teoría de la educación, a la conceptualización de una forma diferente de pensar la educación.

Hay un segundo elemento: los aspectos metodológicos. Lo que la EP propone no es sólo pensar la educación desde otra perspectiva, sino hacer la educación de una forma diferente. Pero la conexión entre el cómo se hace y cuál es la educación que quiero son aspectos claramente relacionados y que tienen, en algunos casos, líneas fronterizas muy difusas.

\section{La International Encyclopedia of Adult Education la define como:}

Un enfoque no formal de la educación de personas adultas que desarrolla en los aprendices la capacidad de analizar críticamente las causas profundas de sus luchas socioeconómicas, políticas, culturales, espirituales y religiosas con el fin último de organizarse y realizar acciones que conduzcan a la transformación social (Turay, 2005, p. 481).

Lo que quiero destacar de esta definición es que se trata de un conjunto de ideas que caracterizan un determinado pensamiento educativo y señalan como debe ser la educación y cuáles son sus finalidades para conectar los procesos educativos con la vida cotidiana de las personas, y con los intentos por transformar esta.

En las siguientes páginas voy a abordar ambas dimensiones - la teoría de la educación y la metodología. Con relación a las cuestiones más teóricas, voy a comenzar señalando algunas de las ideas que se encuentran en los orígenes de la EP, siempre desde la perspectiva de América Latina. Una vez clarificados esos asuntos, dedicaré una segunda sección de este texto a las cuestiones que tienen que ver con las metodologías. 
Las aportaciones a la EP en Latinoamérica en los años sesenta y setenta del pasado siglo son diversas y muy interesantes para poder comprender un poco mejor sus propias características. Un primer elemento es la Teología de la Liberación - fundamentalmente en Brasil, pero no solo. De hecho, no conviene olvidar las profundas raíces cristianas de Paulo Freire y sus enraizadas convicciones religiosas que han sido estudiadas y analizadas, entre otros, por Kirylo y Boyd (2017). La Teología de la Liberación dota de un marco de transcendencia a la EP. Como indican los autores citados.

Las experiencias tempranas en la Acción Católica condujeron a Freire a realizar su trabajo en alfabetización entre los pobres del medio rural [...] Por otra parte, son [estas experiencias en la Acción Católica] el motivo por el que su sensibilidad espiritual llegará a relacionarse intrínseca e íntimamente con el compromiso con el cambio social y la lucha contra la opresión (p. 5).

Podemos ahora ir a otras cuestiones y analizar su influencia en la EP. Siguiendo a Osorio (2020) me voy a detener en dos: a) las teorías de la desescolarización, centradas, pero no solo, en el pensamiento de Ivan Illich; y b) el desarrollo de metodologías como la investigación participativa con el trabajo de Orlando Fals Borda en Colombia y Rodolfo Stavenhagen en México.

He seleccionado estos dos elementos, y no otros, porque entiendo que resumen el carácter alternativo y de búsqueda radical de otro tipo de educación que constituye la EP. Por un lado, la crítica a una escuela clasista y colonizadora del conocimiento. Por el otro, la consideración de la investigación como un acto de creación de conocimiento útil para las personas y las comunidades y que debe valorar los saberes cotidianos.

\section{La desescolarización. Contra una escuela colonizadora}

Aunque centrada de forma mayoritaria en la figura de Ivan Illich y, sobre todo, en su obra más conocida La sociedad desescolarizada, los movimientos por la desescolarización de la sociedad tienen otras figuras representativas (e.g. Reimer, 1976) y un determinado contexto social, cultural y científico. Como señala Tort (2001)

La desescolarización aparece con fuerza, pues, en este contexto de contestación cultural y pedagógica y tiene que ver con la crisis del mito del progreso indefinido o del crecimiento ilimitado ( $p$. 274).

Pero, además, tiene que ver con las crecientes dudas sobre la utilidad de los saberes escolares volveré de alguna forma a esto al hablar de la investigación participativa - y con la consideración de que el sistema escolar es reproductor de las divisiones de clase existentes en la sociedad.

En esta misma dirección encontramos, con un enfoque diferente, otros trabajos. Por ejemplo, Bordieu y Passeron (1977) - en una obra ya clásica - estudiaron como la escuela transmite el pensamiento hegemónico de una sociedad, no solo de forma explícita, sino a través de la organización, las normas, la jerarquía, etc., lo que se ha denominado el currículo oculto (Apple, 1986). Por otro lado, Willis (1988) analizó las contradicciones y la utilidad del conocimiento escolar para las personas, y como la deserción de la escuela se convertía en una solución creativa para determinados grupos de personas jóvenes.

Una vez asumida la crítica de que la escuela - como afirmaron los autores franceses - reproduce la hegemonía y el pensamiento dominante en una sociedad y en un momento concreto, parecen existir dos caminos: la desaparición de la escuela entendida como vehículo de opresión - el camino que van a recorrer los teóricos de la desescolarización - o la transformación de la misma para crear una que ayude a fomentar una conciencia crítica.

No me interesa un análisis exhaustivo de las teorías de la desescolarización, sino como estas teorías influyen en el concepto de EP. Por ello, en las líneas que siguen, voy a centrarme, fundamentalmente, en el trabajo de Ivan Illich como representante de toda esa corriente - más aún como teórico que 
vivió en México y escribió en paralelo a los inicios de la EP. Esto conduce a un cierto reduccionismo, pero creo que ayuda a entender la conformación de la EP como campo teórico.

Señala Illich (1974):

Al alumno [sic] se le "escolariza" de ese modo para confundir enseñanza con saber, promoción al curso siguiente con educación, diploma con competencia, y fluidez con capacidad para decir algo nuevo (p. 7. Entrecomillado en el original).

Y ello, de forma muy resumida, porque la escuela es un instrumento de reproducción de la sociedad capitalista, tanto en un sentido ideológico de reproductor del pensamiento hegemónico, cuanto en el hecho de que no cumple su papel como elemento de movilidad social que garantiza el valor del mérito y el esfuerzo, y el desarrollo de las personas. La opción de Illich es que los grupos populares y comunitarios creen sus propias acciones educativas en paralelo a la escuela 'oficial'.

Con independencia de esta crítica ideológica general, considera que la forma de organización de la escuela da al profesor y a la profesora un poder ilimitado sobre los aprendices. Ese poder abarca todas las esferas de su vida e incluye juicios de valor moral, o simples descalificaciones.

Se hace sentir cada transgresión como un delito múltiple. Se cuenta con que el delincuente sienta que ha quebrantado una norma, que se ha comportado de modo inmoral, y se ha abandonado. A un alumno [sic] que ha conseguido hábilmente ayuda en un examen se le dice que es un delincuente, un corrompido y un mequetrefe (Illich, 1974, p. 69).

La asistencia a clase y el aprendizaje del conocimiento escolar supone que las personas, indica Illich, se ven excluidas de su cotidianeidad, cotidianeidad que nunca entra en la escuela. Se les obliga a aprender conocimientos que no valoran los saberes experienciales que poseen. Un brillante ejemplo de esta falta de valor concedida a la experiencia propia se encuentra en el primer capítulo de Tiempos difíciles (Dickens, [1854] 2008) a cuenta de la definición de lo que es un caballo.

Se trata, por tanto, de desescolarizar la sociedad y no de construir una escuela diferente. Como ya he indicado, la crítica a la escuela no lleva aparejada la búsqueda de una alternativa dentro de la escuela, sino el traspaso de las tareas de la escuela al conjunto de la sociedad. Illich denominó a esta nueva organización 'tramas de aprendizaje'.

Una crítica semejante conduce a muchos a pensar si no será posible concebir un estilo diferente de aprendizaje [...]. O tal vez aprendieron lo que saben por medio del ritual de iniciación de una pandilla callejera, de un hospital, de la redacción de un periódico, de un taller de fontanería o de una oficina de seguros. La alternativa a la dependencia respecto de las escuelas no es el uso de recursos públicos para algún nuevo dispositivo que "haga" aprender a la gente; es más bien la creación de un nuevo estilo de relación educativa entre el hombre [sic] y su medio (Illich, 1974, pp. 144-145. Entrecomillado en el original).

En definitiva, lo que plantea el autor es que los conocimientos se adquieren por medios diferentes y en espacios diversos y que la escuela no tiene ninguna autoridad especial para transmitir conocimientos. Su programa para la organización de un sistema educacional - no habla de escolar - queda resumido de la siguiente forma: i) proporcionar acceso a los recursos educativos en cualquier momento de la vida de las personas; ii) que todas puedan compartir sus conocimientos con quien quiera aprender de ellas; iii) permitir que cualquier persona pueda presentar públicamente sus argumentos.

No existiría un currículo obligatorio, y la tecnología debería ser garante de la libre expresión de las personas. Las 'tramas de aprendizaje' están compuestas de:

Cosas, modelos, [grupos de] iguales y [personas] mayores [que] son cuatro recursos cada uno de los cuales requiere un tipo diferente de ordenamiento para asegurar que todos tengan acceso a él. Usaré las palabras "trama de oportunidad" en vez de "red" para designar las maneras específicas de proporcionar acceso a cada uno de los cuatro conjuntos de recursos (Illich, 1974, p. 152. Entrecomillado en el original). 
En fin, todo se resume en la existencia de esas cuatro tramas. En primer lugar, los servicios de referencia con relación a los objetos educativos, cuya función sería facilitar el acceso a los procesos de aprendizaje. Este tipo de objetos podrían almacenarse en bibliotecas, salas de exposiciones, etc. La segunda trama son las lonjas de habilidades. Se trata de que las personas elaboren una lista de las habilidades que poseen y de las condiciones para poner al servicio de otras estas habilidades, compartiendo el aprendizaje y la enseñanza.

La tercera es el servicio de búsqueda de compañeros. Se trata de un espacio de comunicación que "permita a las personas describir la actividad de aprendizaje a la que dedicarse, en la esperanza de hallar un compañero [sic] para la búsqueda" (Illich, 1974, p. 156).

Por último, la cuarta trama tiene que ver con los servicios de referencia con respecto a educadores independientes. Esto supone la construcción de un catálogo de personas que ejercen alguna profesión y de las condiciones de acceso a sus servicios.

El planteamiento de Illich es, fundamentalmente, la sustitución de la escuela por la comunidad. Es este asunto de la comunidad como fundamento de los conocimientos que se trabajan, y como principal receptor de los mismos, esencial en la concepción de una EP que siempre extrae los temas de estudio los temas generadores en la terminología freireana (Freire, 1985) - de los intereses de las personas como miembros de una comunidad, para hacerlos partícipes y devolver los descubrimientos y aprendizajes. Se trata de buscar caminos educativos diferentes a la escuela y que pasan, entre otros, por la construcción colectiva del conocimiento.

\section{La creación de conocimiento y la investigación participativa}

Como ya he señalado, el otro elemento que dota de significado - y que de alguna forma nace y se desarrolla junto a la EP - es la investigación participativa.

Los orígenes pueden remontarse a los trabajos de Kurt Lewin, y, sobre todo, a la publicación de su trabajo seminal Action research and minority problems (Lewin, 1946). No obstante, hay un acuerdo generalizado en considerar el trabajo de Marja-Liisa Swantz (Swantz; Ndedya y Masaiganah, 2001) con mujeres y personas desempleadas en Tanzania en los años 70 del siglo pasado como una experiencia singular y alejada del enfoque considerado más tecnológico de Lewin (Fals Borda, 1998). De hecho, este alejamiento de la tradición lewiniana tiene una importante connotación política y de conocimiento que sitúa a la investigación participativa junto a los grupos sociales marginalizados dentro de la sociedad

En cualquier caso, y en coherencia con haber situado el foco geográfico de la EP en Latinoamérica, voy a centrarme en dos aportaciones en ese contexto. El primer lugar, la construcción de un discurso descolonizador del conocimiento, en segundo, los trabajos de Orlando Fals Borda.

En 1971, Stavenhagen publicó el artículo Decolonizing applied social sciences. La principal afirmación del autor es que la "teoría social más fructífera [puede ser comprobada] mediante la resolución práctica y cotidiana de los problemas de la vida real" (1971, p. 44). Lo que quiere plantear es que las ciencias sociales deben encontrase al servicio de las personas, y "explorar nuevas vías teóricas y ejercer su crítica intelectual" (p. 50). Esto lleva aparejada "la participación directa de los científicos sociales en la aplicación de sus conocimientos" (p. 53).

La crítica de Stavenhagen, y en mi opinión su principal aportación, es la búsqueda de una ciencia social que estudie las realidades de las personas, les ayude a comprenderlas, y a transformarlas. Esa intención de 'escapar' de la ciencia 'oficial', como antes vimos con Illich en el caso de la escuela, unida a la consideración de un conocimiento puesto al servicio de las personas y las comunidades, son elementos esenciales para comprender la significación de la EP. La otra aportación de la investigación participativa, como veremos ahora, es la construcción colectiva y participativa del conocimiento, y las metodologías que permiten llevar a cabo esa tarea.

Como ya he señalado, uno de los autores de referencia es el sociólogo colombiano Orlando Fals Borda. Fals Borda reflexiona sobre la construcción del conocimiento, la epistemología de los saberes cotidianos (Lucio-Villegas, 2015). Su pregunta básica se refiere al papel de lo que denomina 'ciencia popular'. 
La define como:

El conocimiento empírico, práctico, de sentido común, que ha sido posesión cultural e ideológica ancestral de las gentes de las bases sociales, aquel que les ha permitido crear, trabajar e interpretar predominantemente con los recursos directos que la naturaleza ofrece al hombre [sic] (Fals Borda, 1980, p. 70).

La cuestión de la construcción del conocimiento es muy importante para la EP y las aportaciones de Fals Borda son extremamente inspiradoras. Vamos a detenernos en aquellas que tiene que ver con lo que el autor denomina 'devolución sistemática' y lo que llama Vivencia.

Diferenció cuatro elementos en esa devolución (Fals, 1986). Primero, el diferencial de comunicación, o sea, el hecho de que los materiales y el discurso deben ser presentados de una forma, y con un formato, que permita a las personas leer, comprender, cuestionar y discutir la información que se está presentando.

La segunda regla tiene que ver con la utilización de un lenguaje accesible - que permita a las personas participar. El tercer elemento hace referencia al origen de los temas de investigación. Estos deben partir de los intereses de las personas y las comunidades - tal como ya destaqué al hablar de la EP. Los temas generadores, los puntos de partida desde donde construir los procesos de enseñanza/aprendizaje, deben también partir de los entornos cercanos a las personas, deben cuestionarles y formar parte de su vida cotidiana. Esta organización debe ayudar a comprender su realidad más cercana y, llegado el caso y como indica el aforismo freireano, a transformarla. Nuevamente se puede recordar la crítica de Illich a la escuela como una institución que se encuentra alejada de los intereses y las vivencias de las personas.

Por último, la cuarta regla de la devolución es la utilización de estrategias metodológicas sencillas - que no simples - sin necesidad de construir sofisticados procedimientos que se alejan de la comprensión de las personas.

Pero la investigación participativa es, también, una vivencia. Para Fals (2001) el termino significa la experiencia de vida, la necesidad de equidad en las relaciones entre las personas junto a un cierto toque de humanidad. En resumen, señala el autor, la

Investigación Participativa fue definida [se refiere a un congreso celebrado en 1977 en Cartagena de Indias, Colombia] como una vivencia necesaria para la consecución del progreso y la democracia, un complejo de actitudes y valores que darían sentido a nuestra praxis en el campo (Fals, 2001, p. 31. Cursiva en el original).

Al final, lo que la investigación participativa aporta a la EP es un método específico para construir conocimiento de forma colectiva. Un conocimiento que partiendo de las realidades de las personas debe ser escuchado y, de esa forma, conectar la escuela y la comunidad y dar respuesta a las aspiraciones de los grupos.

Ahora voy a referirme al segundo elemento: las metodologías.

\section{Metodologías de la Educación Popular}

Las metodologías de la EP pueden tener dos aproximaciones. Por un lado, la consideración de los actos educativos como actos de producción de conocimiento - en coherencia con todo lo que he dicho hasta ahora $-y$, por otro, la vinculación de los actos educativos con procesos relacionales. Voy, primero, a plantear como los actos de producción de conocimiento derivan de algunas estrategias utilizadas en la investigación participativa. Luego, me detendré en las técnicas que fomentan el desarrollo de las personas, y la construcción de espacios de relación en los procesos educativos.

\section{Los actos educativos deben ser actos de producción de conocimiento}

Para ampliar las contribuciones metodológicas de la investigación participativa vamos a seguir a Orefice (1987) y lo que llama 'Didáctica Territorial'. Orefice desarrolló esta metodología a partir de una investigación sobre los efectos del vulcanismo en la región de Nápoles, Italia, y como afecta la vida coti- 
diana de las personas creando incertidumbre y un cierto sentimiento de desamparo ante la naturaleza. Consideró diversas etapas dentro del proceso. i) Investigación de base. Construir una lista de usuarios individuales o colectivos - existentes en la comunidad para determinar los destinatarios de la intervención; ii) Investigación Participativa no estructurada. Activar los procesos participativos con la construcción de acciones de sensibilización a través de colectivos representativos de la realidad local; iii) Investigación Participativa estructurada. Por medio de ella se pretende que las personas de la comunidad hagan explícitos sus puntos de vista, analicen el problema bajo sus diferentes aspectos y formulen sus propuestas de intervención con relación al mismo. De esta forma sale a la luz el conocimiento que deriva de su cultura local; iv) Intervención didáctica interdisciplinar. Se trata de confrontar los diversos patrimonios de saberes y, en este caso, plantear qué conocimientos sobre la temática objeto de investigación derivan del conocimiento científico y tecnológico. Para ello, se estableció una comunicación entre los saberes de la comunidad y los elaborados por el conocimiento científico académico, conectando con académicos especialistas en el tema; v) Investigación de la comunidad local. Es la última etapa del trabajo. En ella, se someten a verificación los saberes que provienen de uno y otro tipo de conocimiento. Es el momento, también, en que hay que definir la respuesta que es necesario dar al problema a nivel local. Es, en suma, la culminación del proceso de creación de conocimiento al combinar los dos - el que proviene de las personas de la comunidad y el que deriva de la investigación científica académica- sin que ninguno tenga un carácter dominante sobre el otro.

De alguna forma, esta propuesta mantiene dos de los elementos esenciales de la propuesta de la EP. Por un lado, los asuntos objeto de investigación nacen de las realidades cotidianas de las personas y sus comunidades. En segundo lugar, las personas expertas no adoptan un rol dominante, sino que se establece una relación dialógica que permite una diversidad de enfoques y de soluciones.

Una última contribución que me parece importante es la consideración de que toda acción, todo proyecto de investigación y educación es un espacio de comunicación (Associação in Loco, 2001).

La idea de que todo proyecto se constituye como espacio de comunicación tiene varios sentidos. Por un lado, todo proyecto - podemos sustituir proyecto por acción educativa - debe promover la escucha de las personas - uno de los fundamentos del respecto (Sennett, 2003) -; fomentar la expresión individual; favorecer la negociación y crear un vocabulario compartido.

Favorecer la negociación supone, entre otras cosas, considerar que los espacios comunitarios son lugares de conflicto más que de consenso (Wildemeersch y Vandenabeele, 2007) y que es necesario trabajar los asuntos relacionados con la mediación educativa para alcanzar acuerdos - que no consenso - o, al menos, minimizar los conflictos (Gutiérrez y Prieto, 2002). La consideración del espacio educativo como uno de conflicto es, también, la consideración de que las personas que participan en los procesos provienen de lugares diferentes y que esa diferencia debe ser promovida, garantizada y utilizada como un recurso educativo más, y de ninguna forma debe ser eliminada para cimentar homogeneidades.

Así, el espacio de comunicación se convierte en un espacio de construcción de conocimientos a partir de las experiencias de las personas que participan. Esta creación de conocimiento sólo es posible cuando la realidad entra en la escuela y los saberes construidos son útiles para las personas y para las comunidades.

\section{Metodologías cooperativas para construir conocimiento}

Voy, ahora, a presentar algunas cuestiones generales relacionadas con las metodologías de la EP desde la perspectiva de una tarea de grupo que implica el trabajo sobre los procesos de relación entre las personas - sin los que no existe educación. Quiero destacar que las metodologías de la EP se asientan, fundamentalmente, en tres elementos: diálogo, participación y relaciones cooperativas dentro del grupo y la comunidad.

El diálogo es el corazón de la metodología y la filosofía freireanas. Es el elemento que establece un determinado tipo de comunicación igualitaria y construye procesos educativos cooperativos que se caracterizan por la construcción de interacciones sociales entre las personas participantes. El diálogo 
señala, de alguna forma, el camino por el que nuevas formas de conocimientos son creadas. Como señala Park, "más que una técnica para conseguir un fin es una expresión de la condición humana que mueve a las personas a reunirse" (2001, p. 81).

La participación es una consecuencia del diálogo y las relaciones entre las personas. Es posible que el referente escolar más interesante sea la asamblea, (e.g. Freinet, 1976), a partir de la cual se definen las tareas y se organiza el trabajo a realizar ese día. En el caso de la EP, la participación es un elemento esencial para la de construcción de conocimiento, tanto dentro como fuera de la escuela.

Por último, la utilización de unas metodologías que se fundamentan en el trabajo grupal y cooperativo, considerando la cooperación un elemento natural en la vida de las personas (Sennett, 2012), e indispensable para que se produzcan procesos educativos. Además, las metodologías de la EP aspiran a ser dialógicas, esto es, incluir una diversidad de voces que hagan el diálogo diverso y enriquecedor sin necesidad de llegar a una conclusión unificada (Sennett, 2012). Y esto es así porque la EP "comienza desde los entornos intelectuales, emocionales y físicos de las personas" (Clover, Follen y Hall, 2010, p. 44).

Por otro lado, como señalan estas mismas autoras (2010),

La idea central en la creación de oportunidades de aprendizaje por las personas adultas es el reconocimiento de que los seres humanos tienen muchos sentidos con los que pueden percibir el mundo, así como diversos estilos de aprendizaje (p. 37).

La práctica de la EP parte de los grupos, y de las experiencias acumuladas por las vivencias no solo individuales, sino como participantes en un colectivo que se ha ido construyendo por medio de las relaciones sociales. Quiero destacar que cuando hablo de experiencias estoy refiriéndome a las experiencias que derivan de la vida cotidiana de las personas, lo común, no lo extraordinario, aunque a veces lo común se produzca en ámbitos o situaciones extraordinarias.

Clover, Follen y Hall (2010) se refieren a las acciones educativas como talleres. Aun cuando su trabajo se centra en la educación ecológica de personas adultas, la secuencia en la que organizan los talleres es bastante sugerente y nos proporciona algunas pistas sobre la forma de organizar procesos de EP. Diferencian las siguientes fases:

a) Planificación y preparación. Definir las finalidades y objetivos que se quieren alcanzar con el taller. En la definición de estos objetivos deberían participar las personas y no sólo las educadoras y los educadores. Ello supone que esta fase de preparación conlleva la utilización de herramientas de motivación que deben permitir que salgan a la luz emociones como, por ejemplo, los miedos a aprender, la falta de autoestima y autovaloración, etc.

b) El contexto donde va a realizarse el taller. Supone tener un mínimo conocimiento de la comunidad o grupo donde va a realizarse el taller, y también de las personas que van a participar. También tiene que ver con la elección del lugar donde se va a desarrollar el taller. Más allá de que pueda tener un valor simbólico para las personas, es importante que reúna, también, una serie de condiciones de comodidad, que sean espacios donde exponer las creaciones y actividades que las personas van realizando, y se constituyan en potenciadores de relaciones. También habrá que considerar que el lugar donde se encuentra el local, y los horarios de las actividades sean accesibles a las personas de la comunidad, tanto física como simbólicamente.

c) El conocimiento de las personas que conforman el grupo. La utilización de indicadores demográficos básicos: edad, sexo, nivel de instrucción, ocupación, nivel de renta, agrupamiento familiar, etc. son importantes. Pero también lo es conocer los motivos por los que se asiste, las resistencias de las personas a participar en determinados procesos de enseñanza/aprendizaje, así como sus conocimientos previos.

d) Procesos y contenido. Los contenidos deben partir de los intereses y motivaciones de las personas. Aunque deben definirse unos contenidos que sean guía de todo el proceso, hay que mantener la suficiente flexibilidad para ir introduciendo variaciones sobre la base de la propia 
evolución del grupo que va a hacer que vayan saliendo a la luz nuevos intereses y motivaciones. Además, hay que primar estrategias y herramientas que sean dialógicas y participativas. Para ello, es imprescindible escuchar las historias de las personas.

e) Evaluar lo conocido y aprendido. Los modelos que se engloban bajo la denominación genérica de 'evaluación como iluminación' son los que parecen más adecuados en el caso de la EP. Se trata de comprender como funciona un programa desde una perspectiva contextual e identitaria, y considerando las interpretaciones que las personas participantes hacen de los procesos (Parlett y Hamilton 1976).

Como ya he señalado, la metodología de la EP tiene como una de sus características el trabajo grupal, la conformación de los grupos sociales y comunitarios como espacios y recursos de trabajo. Utilizar el grupo como espacio y como recurso supone tomar en consideración las pautas normales en la constitución de cualquier grupo humano: presentación de las personas; definición de objetivos y normas de funcionamiento; definición de los problemas; toma de decisiones; organización de las tareas; y evaluación de los procesos y los aprendizajes.

\section{A modo de conclusión}

Paulo Freire es una figura capital en la educación popular. Las influencias son mutuas y conforman una línea de pensamiento y acción educativa sin la que no parece posible entender los movimientos y las prácticas de resistencia a modelos que han puesto su foco en la preparación de las personas para el mundo del trabajo y han olvidado que la educación es un acto relacional, que parte de la curiosidad y que debe ser útil para que las gentes puedan situarse en su vida cotidiana con una mejor comprensión de la misma y con herramientas para su transformación.

La recuperación de ese legado de la EP es lo que me parece indispensable en este momento. Un legado que va muy unido al del propio Freire, y al que debemos acercarnos críticamente y valorando la actualidad de un pensamiento - el de Freire y de la EP - muy necesario para reforzarnos contra las peores pesadillas de los modelos neoliberales presentes en un sistema educativo preocupado, básicamente, por incorporar más personas al 'ejercito industrial de reserva'.

Y es aquí donde creo que se encuentra la importancia de recuperar estos asuntos. Las políticas y las prácticas educativas derivadas del aprendizaje a lo largo de la vida se fundamentan en la deshumanización de la persona y su reducción a simple trabajadora o consumidora. La importancia de la EP es ofrecer modelos para resistir esas tendencias deshumanizadoras y construir proyectos educativos que vuelvan a situar a las personas y a las comunidades en el centro. Y también, que devuelvan a la educación su carácter de actividad humana valiosa por sí misma.

Todo ello debe permitir, por ejemplo, enfrentarnos a algunas de las críticas que se hacen al pensamiento de Freire. Como ya señalé más arriba, me centro en dos.

La primera es, sin duda, la que podríamos denominar una crítica ideológica. Las propuestas de la EP no son educativas, sino políticamente adoctrinadoras dicen diversas voces, también en nuestro país. Se trata de una educación que pretende introducir la política en la escuela evitando la transmisión de contenidos que deben ser el objetivo de una escuela 'neutral' y 'apolítica'. Un ejemplo interesante se encuentra, como es lógico, en Brasil en el movimiento de la Escola Sem Partido. Lo que plantea es que en la escuela no se discutan "temas tales como diversidad sexual, género, prejuicio étnico-racial [...] una escuela que no presente visiones diferentes del mundo y de formas de estar en él" (Kohan, 2020, p. 189). Pero no hay que ir hasta Brasil. Las posiciones políticas de determinados partidos en nuestro país buscan que la escuela y la vida personal y comunitaria sean dos compartimentos estancos. En definitiva, que la realidad no entre en la escuela, y sean sólo los conocimientos librescos los que permitan mantener la misma visión de la historia. Un claro ejemplo lo encontramos en relación con el tratamiento que se hace de la Guerra Civil y la Dictadura (Rangel, 2021). 
Desde otra perspectiva diferente, encontramos la escuela centrada en transmitir conocimientos sólo útiles para adquirir la capacidad de ser empleable - ni tan siquiera con la garantía de obtener un trabajo - y no para la vida. Los intereses ideológicos que se encuentran detrás de esta visión intentan producir el mismo efecto: alguien decide lo que es útil y que las personas deben aprender. Pero la gente no toma parte en esta elección y sus intereses quedan siempre supeditados a las competencias que deben adquirir para llegar a ser empleables.

Un segundo elemento de crítica tiene que ver con el papel de la persona educadora. Por un lado, las mismas fuerzas políticas y sociales que se posicionan contra el 'adoctrinamiento en la escuela' proponen dotar de una autoridad indiscutible a la persona educadora - no tanto en base a sus conocimientos o a las metodologías que puede utilizar - para el mantenimiento del orden. En el otro extremo, los documentos de la Unión Europea sobre el 'Aprendizaje a lo largo de la vida' no refieren ya la existencia de una persona educadora. Se habla de practicantes, consejeras, guías, orientadoras, etc. Y todo ello, en muchas ocasiones, ligado a una transmisión mecánica de la EP, y del pensamiento de Freire. Según esta idea mecánica, tanto una como otro diluyeron a la persona educadora dentro del proceso educativo sin que exista diferencia entre ambos - educador o educadora y persona que se educa. Pero lo que, por ejemplo, Freire señala es que la persona educadora es diferente de la que se está educando - no en términos jerárquicos como ahora se pretende $-\mathrm{y}$ debe tener una preparación afectiva y científica.

No puedo estar seguro de lo que hago si no sé cómo fundamentar científicamente mi acción, si no tengo, por lo menos, algunas ideas en torno de lo que hago, de por qué lo hago, y de para qué lo hago (Freire, 1997, p. 40).

Me parece que este segundo elemento de crítica - sobre todo cuando no proviene de transmisiones mecánicas de Freire (Mejía, 2011) - entra dentro de la estrategia de eliminar toda idea de educación y sustituirla por un mero entrenamiento - incluso para las personas educadoras - donde la crítica, el valor de las decisiones éticas, y la expresión de las propias opiniones no tengan cabida - lo que es contrario a todas las concepciones de la EP.

Para terminar, me gustaría insistir en que, aunque los pensadores y pensadoras, las corrientes educativas, culturales, etc. pertenecen a una época determinada y hay que ser muy cuidadoso en analizarlos y considerar siempre ese momento histórico, intelectual, etc., hay propuestas que pueden ser revisitadas. Y esto hay que hacerlo desde una perspectiva que, como el propio Freire (1990) indicó, no puede ser acrítica. En este momento es urgente repensar las aportaciones de la EP, para mantener vivo un pensamiento y unas metodologías que sean útiles para la reflexión, la crítica y la acción transformadora necesaria para alcanzar una mayor justicia social.

\section{Referencias}

Apple, M.W. (1986). Ideología y currículo. Akal.

Associação In Loco (2001). Formação para o desenvolvimiento. Asociación In Loco

Bordieu, P. y Passeron. J.C. (1977). La reproducción. Laia.

Clover, D.; Follen, S. y Hall, B. (2010). La naturaleza de la transformación. Educación ecológica de personas adultas. Publicaciones de la Cátedra Paulo Freire de la Universidad de Sevilla.

Crowther, J. (1999). Popular education and the struggle for democracy. En J. Crowther, I. Martin y M. Shaw (Eds.), Popular education and social movements in Scotland today. NIACE.

Dickens, Ch. ([1854] 2008). Hard Times. Collector's Library.

Fals, O. (1980). La ciencia y el pueblo: nuevas reflexiones. En M.C. Salazar (ed.) (1990), La Investigación Acción Participativa. Inicios y Desarrollo (pp. 65-84). Popular.

Fals, O. (1986). Conocimiento y poder popular. Punta de Lanza/Siglo XXI. 
Fals, O. (1998). Experiencias teórico-prácticas. En O. Fals (comp.), Participación popular. Retos del futuro (pp. 169-236). ICFES.

Fals, O. (2001). Participatory (Action) Research in Social Theory: origins and challenges. En P. Reason y H. Bradbury (eds.), Handbook of Action Research. (pp. 27- 37). Sage Publications.

Freinet, C. (1976). Por una escuela del pueblo. Fontanella.

Freire, P. (1985). Pedagogía del Oprimido. Siglo XXI.

Freire, P. (1990). La naturaleza política de la educación. Poder, educación y liberación. Paidós.

Freire, P. (1997). Professora sim, tia nao. Olho dágua.

Grundtvig, N.F.S. (1991). Selected educational writings. The international people's college and the association of Folk High School in Denmark. (Compilados por Max Lawson).

Gutiérrez, F. y Prieto, D. (2002). La mediación pedagógica. Diálogos.

Illich, I. (1974). La sociedad desescolarizada. Seix Barral.

Kane, L. (1999). Learning from popular education in Latin America. In J. Crowther, I. Martin \& M. Shaw (Eds.), Popular education and social movements in Scotland today (pp. 54-69). NIACE.

Kirylo, J.D. y Boyd, D. (2017). Paulo Freire: His Faith, Spirituality, and Theology. Sense Publishers.

Kohan, W. (2020). Paulo Freire más que nunca. Una biografía filosófica. CLACSO.

Lewin, K. (1946). Action research and minority problems. Journal of Social Issues, 2(4), 34-46.

Lucio-Villegas, E. (2015). Adult Education in Communities. Sense Publishers.

Mayo, P. (1999). Gramsci, Freire and adult education: Possibilities for transformative action. Zed Books

Mejía, M. (2011): Educaciones y pedagogías críticas desde el sur. (Cartografías de la Educación Popular). CEAAL

Orefice, P. (1987). Le Service comunal de Didactique Territoriale. En A. Melo (Org.), Seminario Internacional: Minorías, Áreas, Zonas desfavorecidas. (pp. 337-344). Instituto Politécnico de Faro.

Osorio, J. (2020). La educación popular Latinoamericana: trayectoria, debates y vigencia. En A.A.V.V. Intelectuales y pensamiento social y ambiental en América Latina (pp. 333-348). RIL editores.

Parlett, M. y Hamilton, D. (1976). La evaluación como iluminación. En J. Gimeno y A Pérez Gómez (1989) (Eds.), La enseñanza: su teoría y su práctica (pp. 450- 466). Akal.

Park, P. (2001). Knowledge and Participatory Research. En P. Reason y H. Bradbury (Eds.), Handbook of Action Research (pp. 81-90). Sage Publications.

Rangel, C. (6 de febrero de 2021). Por qué la Guerra Civil y el Franquismo son aún un tabú en las aulas españolas. Huffingtonpost. https://bit.ly/3uo8BzP

Reimer, E. (1976). La escuela ha muerto. Seix Barral.

Sennett, R. (2003). El respeto. Sobre la dignidad del hombre en un mundo de desigualdad. Anagrama.

Sennett, R. (2012). Juntos. Rituales, placeres y política de cooperación. Anagrama. 
Stavenhagen, R. (1971). Cómo descolonizar las Ciencias Sociales. En M.C. Salazar (Ed.) (1990), La Investigación Acción Participativa. Inicios y Desarrollo (pp. 37-63). Popular.

Swantz, M.L.; Ndedya, E. y Masaiganah, M.S. (2001). Participatory Action Research in Southern Tanzania, with special reference to women. En P. Reason y H. Bradbury (eds.), Handbook of Action Research. (pp. 386-395). Sage Publications.

Tiana, A. (2021). Las Misiones Pedagógicas. Educación popular en la Segunda República. Catarata.

Tort (2001). Ivan Illich: la desescolarización o la educación sin escuela. En J. Trilla (Coord.), El legado pedagógico del siglo XX para la escuela del siglo XXI (pp. 271-296). Graó.

Turay, T. M. (2005). Popular Education. En L. M. English (Ed.), International Encyclopedia of Adult Education (pp. 480-484). Palgrave-Macmillam

Wildemeersch, D. y Vandenabeele, J. (2007). Relocating social learning as a democratic practice. En R. Van der Veen, D. Wildemeersch, J. Youngblood, y V. Marsick (Eds.), Democratic Practices as Learning Opportunities (pp. 19-32). Sense Publishers.

Willis, P. (1988). Aprendiendo a trabajar. Como los chicos de clase obrera consiguen trabajos de clase obrera. Akal. 